\title{
MATERIAIS DIDÁTICOS PARA O ENSINO DA MATEMÁTICA NO FINAL DO SÉCULO XIX: UM RETORNO À OBRA DE ABÍLIO CÉSAR BORGES
}

\author{
Luiz Carlos Pais \\ Universidade Federal de Mato Grosso do Sul \\ luiz60pais@gmail.com
}

\begin{abstract}
RESUMO
Este artigo trata do problema dos significados atribuídos aos materiais didáticos para o ensino da matemática elementar, no contexto brasileiro dos últimos anos do século XIX. Mais especificamente, analisa o chamado aparelho múltiplo escolar, um conjunto de recursos, criado e divulgado pelo educador Abílio César Borges, o Barão de Macaúbas. Os resultados indicam que no contexto da expansão da educação popular no Brasil, a difusão do mencionado aparelho ocorreu em colégios particulares. Expressou uma apropriação do método intuitivo, visando materializar aspectos abstratos da matemática escolar. A materialidade do recurso didático simbolizava a modernização da instrução escolar da época considerada.
\end{abstract}

Palavras-chave: Aparelho múltiplo escolar. Materiais didáticos. Didática da Matemática.

\section{MATERIALS FOR THE TEACHING OF MATHEMATICS AT THE END OF THE 19TH CENTURY: A RETURN TO THE WORK OF ABÍLIO CÉSAR BORGES}

\begin{abstract}
This article deals with the problem of the meanings attributed to didactic materials for the teaching of elementary mathematics, in the Brazilian context of the last years of the 19th century. More specifically, it analyzes the so-called multiple school apparatus, a set of resources, created and disseminated by the educator Abílio César Borges, the Baron of Macaúbas. The results indicate that in the context of the expansion of popular education in Brazil, the diffusion of this apparatus took place in private colleges. He expressed an appropriation of the intuitive method, aiming at materializing abstract aspects of school mathematics. The materiality of the didactic resource symbolized the modernization of the schooling of the time considered.
\end{abstract}

Keywords: Multiple school apparatus. Teaching materials. Didactics of Mathematics

\section{MATERIAL DIDÁCTICO PARA LA ENSEÑANZA DE LA MATEMÁTICA EN EL FINAL DEL SIGLO XIX: UN RETORNO A LA OBRA DE ABÍLIO CÉSAR BORGES}

\section{RESUMEN}

Este artículo trata del problema de los significados atribuidos a los materiales didácticos para la enseñanza de las matemáticas elementales, en el contexto brasileño de los últimos años del siglo XIX. Más específicamente, analiza el llamado aparato múltiple escolar, un conjunto de recursos, creado y divulgado por el educador Abílio César Borges, el Barón de Macaúbas. Los resultados indican que, en el contexto de la expansión de la educación popular en Brasil, la difusión del

Rev. Iberoam. Patrim. Histórico-Educativo, Campinas (SP), v. 05, p. 1-18, e019019, 2019. 
mencionado aparato ocurrió en colegios privados. Expresó una apropiación del método intuitivo, buscando materializar aspectos abstractos de las matemáticas escolares. La materialidad del recurso didáctico simbolizaba la modernización de la instrucción escolar de la época considerada.

Palabras clave: Aparato múltiple escolar. Materiales didácticos. Didáctica de las matemáticas.

\section{MATÉRIEL POUR L'ENSEIGNEMENT DES MATHÉMATIQUES À LA FIN DU XIXe SIÈCLE: UN RETOUR AU TRAVAIL D'ABÍLIO CÉSAR BORGES}

\section{RÉSUMÉ}

Cet article traite du problème des significations attribuées aux matériels didactiques pour l'enseignement des mathématiques élémentaires, dans le contexte brésilien des dernières années du 19ème siècle. Plus précisément, il analyse le soi-disant appareil scolaire multiple, un ensemble de ressources créées et diffusées par l'éducateur Abílio César Borges, baron de Macaúbas. Les résultats indiquent que dans le contexte de l'expansion de l'éducation populaire au Brésil, la diffusion de cet appareil a eu lieu dans des collèges privés. Il a exprimé une appropriation de la méthode intuitive visant à matérialiser des aspects abstraits des mathématiques scolaires. La matérialité de la ressource didactique symbolisait la modernisation de la scolarisation de l'époque considérée.

Mots-clés: Dispositif scolaire multiple. Matériel didactique. Didactique des mathématiques.

\section{INTRODUÇÃO}

Os materiais didáticos para ensino da matemática constituem uma ampla temática da história da educação, envolvendo aspectos em sintonia com o contexto social no qual são produzidos e apropriados das mais variadas formas. São recursos cujos significados estão enraizados nas práticas docentes, permitindo estabelecer relações com os métodos, valores, conteúdos, exercícios e com as finalidades previstas para a disciplina. Por esses motivos, sem perder de vista o contexto considerado, a história desses materiais permite estudar traços das culturas e das disciplinas no sentido proposto por Chervel (1998) e Julia (2001).

O caso analisado neste artigo prioriza uma abordagem histórica de materiais didáticos para o ensino da matemática, em nível correspondente aos atuais anos iniciais da educação básica, criados ou adaptados pelo educador baiano Abílio César Borges (1847-1891), o Barão de Macaúbas, os quais foram amplamente divulgados do final do século XIX. Após o seu falecimento, seus materiais foram ainda divulgados até o final da década de 1920, quando surgiram os primeiros sinais do pensamento pedagógico da Escola Nova.

Rev. Iberoam. Patrim. Histórico-Educativo, Campinas (SP), v. 05, p. 1-18, e019019, 2019. 
A abordagem cultural das disciplinas escolares favorece uma visão integradora, no sentido de contemplar dois aspectos fundamentais a serem articulados pelo historiador. Um deles diz respeito às especificidades do tema pesquisado, no nosso caso, materiais didáticos para o ensino da matemática. $\mathrm{O}$ outro aspecto consiste no desafio de mergulhar no contexto cultural mais amplo, no qual as especificidades do tema estavam inseridas no passado.

A análise dos materiais didáticos para o ensino pressupõe o desafio de identificar e analisar as suas origens e, sobretudo, na época considerada, quando a França exercia grande influência no pensamento pedagógico predominante nos colégios particulares do Brasil. Assim, a temática em questão passa pela especificidade da atividade docente, restrita aos saberes e principalmente às silenciosas práticas profissionais dos professores, as quais são cultivadas, sem muito alarde, no embate constante com outros poderes articulados entre instituições que nem sempre estão próximas à realidade da ação docente.

\section{PROBLEMA DE PESQUISA}

O problema que motivou a redação deste artigo consiste em analisar os significados atribuídos aos materiais didáticos indicados para o ensino da matemática escolar, cujas sequências de produção, divulgação e apropriação estão inseridas em uma complexa rede de referências sociais e culturais. Trata-se de um problema histórico de longa duração, cuja existência pode ser identificada em diferentes épocas da centenária história da educação matemática escolar. Desde que surgiram as primeiras sistematizações do sistema de numeração decimal, por exemplo, é possível identificar a invenção de diferentes ábacos usados como recursos para o estudo dos números e das operações elementares da aritmética, simbolizando a abertura de novas possibilidades de acesso ao conhecimento.

Os significados atribuídos a um dado material didático envolvem valores, ideias, concepções, entidades que explicam e justificam a sua produção e utilização. Assim, para evidenciar o problema analisado neste artigo é bom ressaltar a existência de diferentes termos usados na linguagem comum com significados próximos: modelos, artefatos, instrumentos, ferramentas, aparelhos, recursos, dispositivos, tecnologias, entre outros. No caso dos materiais concretos, é importante considerar o quanto esses recursos são realmente expressões de uma cultura

Rev. Iberoam. Patrim. Histórico-Educativo, Campinas (SP), v. 05, p. 1-18, e019019, 2019. 
material, no sentido de sua efetiva circulação e apropriação por parte dos professores inseridos em um determinado domínio social.

Ao descrever a história da nova história cultural, na fase referente aos anos 1970, Peter Burke destaca o interesse renovado de estudos das culturas materiais e de suas relações com as representações simbólicas associadas. No quadro da virada antropológica, ocorrida na mencionada época, teve início diferentes pesquisas sobre essa temática que, décadas depois, motivam o estudo descrito neste artigo (BURKE, 2008).

Ao tomar como referência a cultura predominante no ensino da matemática, de modo geral, pode-se conceber a existência de uma comunidade interpretativa para a qual a leitura dos textos não deve ser concebida como abstrata (CHARTIER, 2003). Nesse caso, estamos considerando textos pedagógicos que acompanham os materiais, expondo argumentos para justificar a sua utilização. Não resta dúvida que as diferentes possibilidades de leitura abrem espaço para uma reflexão bem ampla, porque os significados efetivamente atribuídos a um determinado instrumento podem divergir dos argumentos e explicações formais.

Quanto à definição do problema enunciado, as dificuldades próprias da linguagem associada às práticas de valorização dos materiais didáticos nos levaram a relacionar três noções que extraímos da teoria linguística de Saussure (2002). O recurso didático tem uma componente simbólica que pode ser estudada a partir de três aspectos interligados, que são: significante, significado e significação. Estamos relacionando os significantes aos recursos didáticos em si mesmo, no caso específico daqueles dotados de alguma materialidade. Os significados, eixo principal do problema histórico pesquisado, são as entidades abstratas, tais como crenças, valores, concepções, entre outras, que justificam a utilização dos recursos. A significação traduz a maneira particular através da qual um determinado material foi efetivamente utilizado por um professor, o que nem sempre corresponde às suas finalidades previstas nos textos pedagógicos ou didáticos. De certo modo, a abordagem cultural no caso das disciplinas escolares requer constantes articulações entre esses três polos de reflexão que interligam as apropriações docentes, traduzidas na prática da sala de aula, a parte externa e perceptível dos materiais didáticos e seus significados teóricos descritos nas obras didáticas. 


\section{REFERÊNCIAS TEÓRICAS E METODOLÓGICAS}

A história das disciplinas e culturas escolares constitui um vasto campo de pesquisa, com amplo potencial de problematização, no sentido de permitir uma visão integradora de diferentes elementos relacionados aos saberes docentes. No quadro das mudanças resultantes da virada antropológica dos anos de 1970, foram lançadas as bases de um olhar inovador e até mesmo acentuado, em certo sentido, valorizando a capacidade da escola como instituição produtora de uma cultura específica e original. Entendemos que o momento exigia esse tipo de reconhecimento da originalidade da cultura escolar, pleiteada pelo historiador francês André Chervel, procurando envergar a vara para a posição oposta à uma visão equivocada e reacionária que consiste em conceber a escola apenas como instituição consumidora de saberes e práticas eruditos ou acadêmicos (CHERVEL, 1998).

Após a difusão inicial da teoria formulada por André Chervel, uma contribuição importante foi dada por Dominique Julia, no sentido de reconhecer a potencialidade da noção de cultura escolar, incorporando e atribuindo certa centralidade às práticas docentes, como categoria de grande importância na constituição dos saberes profissionais dos professores. Na continuidade das pesquisas voltadas para a compreensão das culturas de grupos sociais específicos, dos anos 1980, Julia participou desse movimento de valorização das práticas docentes e do seu funcionamento na constituição das culturas e dos embates vivenciados no campo de atuação profissional dos professores (JULIA, 2001).

A inserção das práticas e das representações simbólicas como recursos conceituais para análise histórica, na linha teorizada por Dominique Julia, sinalizou de um movimento mais amplo, identificado por Peter Burke como nova histórica cultural, que se intensificou a partir dos anos 1970. Cumpre observar que Pierre Bourdieu, um dos participantes desse movimento, também se insere no quadro de valorização das práticas como categoria de grande importância para a leitura histórica de domínios sociais específicos. Desse modo, a história das culturas escolares conquistou novas possibilidades, no quadro da nova história cultural, incluindo o reconhecimento da identidade de grupos sociais e a constante luta em busca de sua distinção, conceito trabalhado por Pierre Bourdieu (BURKE, 2008).

Ao estudar a história dos materiais didáticos do final do século XIX, no ensino da matemática elementar, somos levados a indagar sobre a possibilidade de considerá-los como 
objetos da cultura material escolar, no sentido definido por Alves (2010). Fazemos esse destaque porque afinal não é fácil definir o que é cultura, com o mesmo formalismo da visão clássica da matemática que ainda exerce influência considerável na educação matemática. Por outro lado, não basta considerar o termo como uma noção fundamental, como se isso pudesse nos livrar dos eternos retornos para entender o conceito, que emerge de dois movimentos associados e opostos: a objetivação que consiste no afastamento das concepções pessoais e a subjetivação que consiste nas ações do sujeito interessado em aprender o entendimento predominante em um determinado grupo social.

A abordagem proposta pelo referido historiador permitiu um mergulho no domínio interno da disciplina escolar, sem perder de vista os diferentes vínculos existentes com outras instituições além da própria escola. Um dos desafios dessa referência consiste em entender o funcionamento das fronteiras culturais, as quais os professores são levados a respeitar e transgredir no exercício cotidiano da sua atividade profissional. Por esse motivo, as noções propostas pelo referido autor, na década de 1980, foram objeto de uma importante discussão nos anos seguintes, no sentido de melhor visualizar a participação do professor, como protagonista das culturas escolares e não como consumidores (CHERVEL, 1998).

André Chervel observou que o problema das disciplinas escolares não era apenas um tema que havido sido deixado de lado pelos historiadores da educação. Era necessário propor uma nova concepção de história do ensino, tomando os conteúdos como elementos associados a vários outros e que, conjuntamente, constituíam as disciplinas. Em outros termos, foi aberto um novo espaço de investigação histórica, onde as especificidades de cada saber ensinado deixaram de ser concebidas apenas como um apêndice ou uma peça acessória da instituição. Pelo contrário, trata-se de estabelecer como pressuposto básico, a constante articulação entre a parte interna de cada disciplina e seus vínculos com outras referências instituições externas, que certamente transcendem as fronteiras da escola.

A escolha que fazemos do referencial proposto por André Chervel justifica-se pelo fato dos instrumentos conceituais pertinentes para entender o funcionamento das disciplinas escolares. Quase nada pode ser concebido de modo isolado, em se tratando do desafio docente de compreender o funcionamento da matéria com a qual interage durante toda a sua trajetória de vida profissional. Os conteúdos estão associados aos métodos de ensino, assim como os caminhos metodológicos expressam valores, concepções, princípios que permitem viabilizar os objetivos. É 
nessa articulada rede de elementos constituintes da disciplina que os materiais de ensino estão inseridos.

Como alcançar as finalidades previstas para a disciplina escolar ou para a formação desejada pela sociedade, avalista institucional da escola, sem entender o funcionamento de um organismo complexo, repleto de sutilezas epistemológicas, históricas, culturais, entre muitas outras, composto de vários elementos, que vão muito além dos conteúdos listados em programa de ensino ou plano de estudo? Na linha proposta por Chervel (1998), uma das tarefas capitais consiste em analisar os componentes internos das disciplinas, assim como as finalidades que justificam a existência de um conjunto autônomo de conhecimentos. Não resta dúvida que o ensino da matemática, como disciplina escolar, desde os mais remotos tempos, ocupa um espaço considerável na aculturação das massas, sem perder de vista as finalidades sociais atribuídas aos estudos escolares. Nós, participantes do movimento da educação matemática, somos os únicos profissionais em condições de mergulhar nesse profundo oceano histórico para melhor conhecer as raízes culturais do nosso ofício.

Ao definir os parâmetros de uma abordagem histórica das culturas escolares, não é evidente entender o funcionamento interno das disciplinas, suas finalidades e os diversos elementos sutis que nem sempre a visão externa consegue entender. Esse é o caso da defesa apaixonada do estudo dos teoremas, como elemento essencial da matemática dos anos finais do ensino fundamental, caso predomine a opção metodológica tradicional. Entretanto, nem todas as sutilezas da argumentação matemática são explicitamente textualizadas, fazendo com que o professor não deva se basear apenas em textos oficiais para entender as finalidades do ensino.

Entre as disciplinas criadas pela escola para atender as finalidades sociais que lhes foram confiadas, a partir do final do século XIX, estava a matemática, sendo concebida como instrumento para o aluno poder se aproximar da modernidade anunciada pelo novo século que se aproximava. Nesse quadro, as disciplinas passam a ser concebidas como entidades formadas por elementos específicos. Diante da nossa temática de estudo, inserida no campo da educação matemática, nos compete entender os principais elementos que viabilizaram os primeiros movimentos do ensino da matemática no quadro da educação popular.

Uma considerável fonte de influência do pensamento pedagógico do final do século XIX e início do século seguinte diz respeito ao método intuitivo e suas variações em função das especificidades das matérias ou conteúdos de ensino. A partir da influência da França, o Brasil e

Rev. Iberoam. Patrim. Histórico-Educativo, Campinas (SP), v. 05, p. 1-18, e019019, 2019. 
outros países sonhavam com o glamour da época, onde foram criados vários produtos tecnológicos que marcaram a modernidade inicial do século XX. Porém, nem tudo estava em pleno equilíbrio social, havia muitas injustiças e parte da riqueza europeia ainda estava calcada na existência de muitos povos colonizados. No Brasil, ainda imperava o pensamento escravocrata e a divisão entre a elite social e as grandes massas desprovidas de acesso à educação escolar. Tudo isso fez com que o sonho da chamada bela época acabasse com o início da Primeira Guerra Mundial (1914-1919).

Os anos 1870, quando o Segundo Reinado já estava em decadência, foi o momento inicial de criação e divulgação dos livros e materiais inventados por Abílio Borges. Nesse momento, os países desenvolvidos da Europa e os Estados Unidos estavam empenhados em criar uma nova modalidade de escola para atender as classes populares. Algo que ainda não havia acontecido, no sentido de levar grandes populações de crianças aos bancos escolares, abarcando diversos tipos de problema. Entre os quais a formação docente, a apropriação de métodos, a produção de livros e materiais que pudessem ser utilizados. São observações que nos auxiliam a aproximar do tempo em que o referido educador criou seus materiais didáticos para o ensino da matemática elementar, reunindo-os em um conjunto batizado de aparelho múltiplo escolar. Esses inventos expressam a maneira como o autor apropriou-se do método intuitivo e das lições de coisas (SCHELBAUER, 2006).

Os procedimentos metodológicos adotados na produção deste artigo consistiram em uma abordagem crítica, inspirada nas indicações propostas por Bloch (2002) e compartilhada por outros historiadores que pertencem ao mesmo movimento historiográfico. Trata-se de considerar algumas noções propostas pelo referido autor, considerando possíveis incorporações que surgiram posteriormente, principalmente, no período inicial da terceira geração do movimento dos Annales, no qual ocupou posição de destaque o historiador francês Jacques Le Goff . Em outros termos, a partir dos anos 1970, com a ampliação do interesse pela história cultural, abre-se espaço para o destaque das especificidades e suas articulações com os contextos sociais onde a história está inserida.

Na redação deste artigo optamos em fazer uma abordagem crítica, cujos traços gerais são destacados por meio do que entendemos como alguns postulados que pretendemos seguir na análise das fontes acessadas. O primeiro postulado diz respeito à dúvida examinadora, conceito proposto por Bloch (2002), ao esboçar os caminhos para uma análise crítica na história. Em seguida, estamos empenhados em cultivar a faculdade de observação, interrogar os testemunhos, diferenciar

Rev. Iberoam. Patrim. Histórico-Educativo, Campinas (SP), v. 05, p. 1-18, e019019, 2019. 
documentos e monumentos, bem como aproximar e diferenciar contextos diferentes para tentar melhor entender o passado.

\section{TRAJETÓRIA DE UM EDUCADOR}

Abílio César Borges nasceu no dia 9 de setembro de 1824, no arraial de Macaúbas, vinculado à vila de Nossa Senhora do Livramento das Minas do Rio de Contas, na província da Bahia. Iniciou o curso de medicina na Faculdade de Salvador e transferiu-se para o Rio de Janeiro, onde concluiu sua formação médica, em 1847, mas sempre exerceu o magistério durante sua vida de estudante. Ao estilo da época, defendeu sua tese intitulada Proposições Sobre as Ciências Médicas, discursada diante da ilustre sociedade da corte imperial. Chegou a exercer a medicina nos interiores remotos da Bahia, por pouco tempo, até resolver se dedicar integralmente à carreira do magistério escolar (ALVES, 1936).

Foi nomeado diretor geral de estudo da província da Bahia, em 1856. Pouco tempo depois, apresentou ao presidente da mesma província um extenso relatório com as questões que julgava ser as mais urgentes para melhoria da instrução pública. Registrou no relatório a importância do professorado, de melhorar as condições de formação através do sistema dos adjuntos, defendendo a melhoria do salário pago aos professores baianos que então ganhavam 400 mil reis anuais no interior e 600 mil reis na capital. Sugeriu ao governo a criação de um montepio em favor da velhice dos professores, entre outras ideias avançadas para o seu tempo, tal como condenar os castigos físicos aplicados aos alunos.

Ao exercer o cargo de diretor geral dos estudos, defendeu a distribuição gratuita de periódicos pedagógicos aos professores públicos para que eles pudessem acompanhar os modernos métodos de ensino e os materiais indiciados para o ensino elementar. Detalha ainda em seu relatório questões relativas à moralidade, ao ensino da doutrina cristã, aos prédios escolares, entre outros temas. Porém, cumpre observar que nesse relatório de 1856, ainda não aparecia, de modo explícito, o seu ideário pedagógico em favor do uso docente de livros e materiais de ensino, visando formar as doutrinas previstas na instrução escolar.

Devidos às suas posições radicais em defesa do ensino da religião católica, defendeu a obrigatoriedade dos professores das escolas públicas e particular levarem seus alunos à missa, uma vez por semana. Como diretor da instrução pública da Bahia causou acirrada polêmica ao suspender

Rev. Iberoam. Patrim. Histórico-Educativo, Campinas (SP), v. 05, p. 1-18, e019019, 2019. 
o diretor de um colégio particular que costumava de participar de alguns jogos e diversões com os seus alunos. Pouco tempo depois, o diretor punido conseguiu na justiça o direito de retornar à direção do colégio, causando profunda indignação no futuro Barão de Macaúbas. Por esse e outros motivos, resolveu deixar Salvador para morar no Rio de Janeiro, onde já cultivava muitos amigos próximos à corte imperial.

Em meados da década de 1860, quando ainda residia em Salvador, Abílio Borges fez sua primeira viagem à Europa, onde visitou escolas, adquiriu obras pedagógicas, conheceu novos métodos e materiais de ensino. Posteriormente, retornou outras vezes à Europa, sempre empenhado em conhecer o que havia de mais moderno na instrução escolar.

Em $1^{\circ}$ de agosto de 1871 , inaugurou o primeiro Colégio Abílio, no Rio de Janeiro, em sociedade com o professor Epifânio Reis. Entre 1871 a 1878, dirigiu o colégio participou do conselho diretor da instrução do município da corte. Entretanto, houve divergências na sociedade mantenedora do colégio, razão pela qual o contrato societário foi desfeito em 1878. O nome do estabelecimento passou a ser então Colégio Epifânio Reis. No ano seguinte, o educador seguiu para mais uma viagem à Europa.

Em 15 de dezembro de 1877, deu uma entrevista ao Jornal do Comércio, do Rio de Janeiro, demostrando desânimo e cansaço de sua caminhada no campo da educação e dos diferentes embates enfrentados em defesa do que entendia ser melhor para as crianças.

O segundo Colégio Abílio foi fundado, em 1881, na cidade mineira de Barbacena. Havia uma epidemia de febre amarela no Rio de Janeiro e o clima da cidade mineira oferecia melhores condições para a saúde dos alunos internos. Esse colégio funcionou até 1888, quando o educador já com a saúde abalada retornou para o Rio de Janeiro.

O terceiro Colégio Abílio foi aberto no Rio de Janeiro, em 15 de março de 1883, sob a direção de Abílio César Borges Filho (engenheiro civil) e Joaquim Abílio Borges (bacharel em direito), filhos do ilustre educador Barão de Macaúbas. Usando as mesmas estratégias adotadas pelo pai, ambos visitaram os Estados Unidos, de onde trouxeram obras pedagógicas e materiais considerados os mais modernos daquele momento. Foi publicado na imprensa que o estabelecimento estava em condições de proporcionar educação científica e literária, em vista dos modernos aparelhos de ensino importados dos Estados Unidos. No mesmo ano de inauguração do colégio, foi realizada a grande Exposição Pedagógica do Rio de Janeiro, com a participação de diferentes países, na qual o Colégio Abílio participou com a exibição de materiais didáticos

Rev. Iberoam. Patrim. Histórico-Educativo, Campinas (SP), v. 05, p. 1-18, e019019, 2019. 
utilizados em suas aulas e conferências ministradas tanto pelo pai, Abílio César Borges, como pelo seu filho Joaquim Abílio Borges. Esse estabelecimento fundado em 1883 funcionou até 1911, ou seja, cerca de 20 anos após o ilustre educador.

Abílio Borges publicou 14 livros escolares de sua autoria, alguns deles alcançando grande número de edições. Em 1876, lançou o livro Desenho Linear ou Geometria Prática Popular, com prefácio dirigido aos professores, defendendo a importância do ensino do desenho, de modo criativo, criticando a prática de levar os alunos a fazerem cópias, de modo automatizado, sem estimular a criatividade e senso de observação. Para autor, ao ensinar o desenho, o professor devia explorar a imaginação do aluno, levando-o ao exercício do senso de observação, sem a pretensão de formar um artista ou um desenhista profissional. Outro aspecto descrito na obra, era o exercício de levar o aluno a ler o desenho, no sentido de desenvolver a habilidade de reconhecer partes específicas e elementos gráficos.

Além dos livros de sua autoria, o educador divulgava livros de outros autores. Esse é o caso do livro Noções de Geometria para compreensão do desenho linear, de autoria do professor major engenheiro Manoel da Silva Pereira, dedicando a obra ao ilustre educador baiano que, regularmente, estava divulgando seus materiais por diversas províncias. De modo análogo, o livro intitulado Noções de Aritmética e do Sistema Métrico Decimal, do professor Manoel Rodrigues da Costa, formado na Escola Normal da Bahia, aparece na coleção de textos adotados no Colégio Abílio, onde o autor exercia o magistério.

$\mathrm{Na}$ época considerada, havia uma ampla defesa pedagógica quanto à necessidade da utilização de materiais didáticos como uma condição material para viabilizar o ensino da matemática, tornando os conceitos e operações mais significativos para o aluno. Na linguagem pedagógica e na nomenclatura da disciplina era usual diferenciar os números abstratos dos números concretos, usando essa última expressão para designar a quantidade de objetos concretos existentes em uma dada coleção.

Nesse sentido, Abílio Borges afirmava em suas conferências que todo esforço deveria ser feito pelo professor, no sentido de tentar apoiar o raciocínio do aluno em materiais, tanto no ensino dos números, das operações elementares, da geometria prática e do sistema métrico decimal. Em diferentes oportunidades fez críticas aos tratados pedagógicos, que, segundo sua opinião, abordavam aspectos teóricos, sem contribuir na solução dos problemas práticos, vivenciados pelos 
professores dos sertões. Expressão essa que usava desde os tempos em que foi diretor de instrução pública da província da Bahia.

Nas mesmas conferências, manifestava restrições aos métodos divulgados por Pestalozzi, Froebel e Montessori, entendendo que suas obras estavam muito distantes da realidade de grande maioria dos professores brasileiros. Desse modo predominava uma certa representação social de desalento e ceticismo quanto à possibilidade de grande parte dos professores se apropriar das teorias pedagógicas da época.

Diante do desafio de contribuir na solução dos problemas da instrução escolar, o autor se empenhou em apropriar-se dos pressupostos metodológicos da época, com destaque para o método intuitivo e para as lições de coisas. Nesse sentido desenvolveu suas estratégias de produção e divulgação de materiais e livros escolares, de modo que esses fossem de fácil utilização pelos chamados professores dos sertões. Muitos desses mestres-escolas tinham formação prática, adquirida como adjuntos de outros professores, por certo tempo, até conseguirem sua nomeação para reger uma escola. Razão pela qual, além da indicação de livros e de materiais de ensino, admitia-se a necessidade de as orientações pedagógicas serem transmitidas de maneira clara e direta para orientar a prática do professor.

Os postulados discursivos eram apresentados em suas conferências pedagógicas e amplamente repetidos por seus admiradores e apoiadores, quase sempre, muito próximos aos poderes da corte. A título de exemplo, um desses postulados consistia em defender que os aparelhos escolares tinham a função de desenvolver a capacidade de observação dos meninos, evitando dessa maneira o estudo abstrato e estéril (apud ALVES, 1936).

Desse modo, acreditava que os materiais tinham o poder de evitar o que chamava de vício da verbosidade, no sentido de a lição ser proferida apenas como uma sucessão de exposições verbais, sem sentido para os alunos. Além do mais, afirmava que essa prática indevida em nada contribuía para o desenvolvimento do raciocínio necessário para fazer do menino um homem honrado. Posição contraditória, de certo modo, com a visão fortemente escolástica no plano moral e religioso que predominou, por longos anos, na trajetória do educador agraciado com o título de Barão de Macaúbas. 


\section{APARELHO MÚLTIPLO ESCOLAR}

Entre os materiais inventados por Abílio César Borges está o chamado aparelho múltiplo escolar, divulgado em diferentes jornais da década de 1880 como instrumento para a modernização dos métodos de ensino. Esse material foi uma das atrações da Exposição Pedagógica do Rio de Janeiro de 1883, como observamos, mesmo antes da fundação do terceiro Colégio Abílio, quando a utilização do material foi demonstrada em conferência proferida pelo educador, a qual contou com a honrosa presença do Imperador. Esse aparelho reunia um conjunto de materiais destinados ao ensino de diferentes matérias, comercializado dentro de uma grande caixa de madeira, cuja tampa funcionava suporte para fixação das peças a serem exibidas para os alunos. Era composto pelos seguintes elementos:

Um ábaco usado para o ensino dos primeiros números e operações; um fraciômetro, conjunto de setores circulares para o estudo das frações; um ábaco com eixos verticais e horizontais, batizado de contador vértico-horizontal; um aparelho cromático, disco com setores coloridos para o estudo da luz; um conjunto de carimbos com letras e números, chamado de impressão escolar; um quadro negro pequeno; um suporte para mapas; um conjunto de sólidos geométricos; um conjunto de cavilhas, pequenos bastões cilíndricos usados para contagem; tabelas com símbolos alfabéticos e numéricos; quadros para o estudo do sistema métrico decimal; um conjunto de instrumentos de desenho. (ALVES, 1936).

Apesar de diversas tentativas que fizermos não foi possível localizar uma imagem ou uma fotografia desse conjunto de materiais, o que seria desejável para ampliar o poder de comunicação deste texto. Entretanto, há de se convir que na época considerada não era comum fotografias de materiais escolares.

Quanto ao contador vértico-horizontal, trata-se de dispositivo perfilado, com extrema proximidade ao ábaco inventado pela educadora francesa Marie Pape Carpentier (1815-1878), criadora das chamadas escolas maternais e autora de tratados pedagógicos. Aspecto que aparecem em comentários publicados na imprensa da época, ao considerar que o Barão teve o mérito de adaptar o material às condições de sua utilização no Brasil. Ao invés de usar ábacos com arames ou eixos horizontais, a referida educadora teve a ideia de curvar as hastes de arame, em forma da letra "L", com as extremidades fixadas na moldura de madeira, de modo que esferas de madeira pudessem ser movimentadas de um lado para outro. 
A divulgação do aparelho pelo seu inventor despertava grande interesse por parte dos professores. Mas o seu custo não era acessível à grande maioria dos professores públicos, razão pela qual há indícios de alguns professores estavam construindo seus próprios aparelhos, uma tática de reprodução, para se apropriarem dos modernos métodos de ensino.

A descrição detalhada dos componentes do aparelho múltiplo escolar foi objeto de uma reportagem publicada no Jornal do Brasil, do Rio de Janeiro, edição de 30 de setembro de 1883, no contexto da exposição pedagógica realizada por aqueles dias. Foi destacado a conferência proferida pelo pedagogo, assistida por autoridades, intelectuais, professores e diretores de escolas. No caso específico do fraciômetro, foi afirmado que parte do aparelho tinha uma invenção próprio do conferencista. A mesma reportagem foi reproduzida no jornal O Paiz, de São Luiz do Maranhão, em 25 de outubro do mesmo ano.

Quanto à divulgação dos materiais, dois anos após a Exposição Pedagógica, foi realizada uma sessão escolástica infantil, no salão nobre do Museu Pedagógico, na tarde do domingo, 12 de outubro de 1885. O objetivo dessa sessão era demonstrar a eficiência do aparelho múltiplo escolar. Um anúncio publicado no Diário de Notícias, do Rio de Janeiro, em 9 de outubro de 1885, registra a conferência de divulgação do aparelho, com a estratégia de recorrer à demonstração das operações feitas pelas crianças. Esse evento foi divulgado nos seguintes termos: “[...] será realizado no Museu Pedagógico, na presença de Sua Majestade o Imperador, uma sessão escolástica infantil dos alunos do Colégio Abílio, que trabalharam com o Aparelho Múltiplo Escolar, inventado pelo senhor Barão de Macaúbas.” (DIÁRIO DE NOTÍCIAS, 9 out. 1885, p. 12).

Uma estratégia usada para divulgar o aparelho, convidando o Imperador, o diretor da instrução primária e secundária do Rio de Janeiro, o ministro do império, entre outras autoridades, bem como os professores e pais de alunos. Para abrilhantar o evento, houve a apresentação da banda de música formada pelos alunos do Colégio Abílio. Outros alunos cantaram em coro para saudar a presença do público. Outros detalhes da mesma conferência constam em artigo publicado no jornal O Paiz, de São Luiz do Maranhão, de 13 de novembro de 1885, cuja íntegra transcrevemos abaixo:

Como fora anunciado, o Barão de Macaúbas fez ontem a primeira conferência no salão do Museu Pedagógico, na presença de Sua Majestade o Imperador, de Sua Alteza o Senhor Conde d'Eu, do ministro da marinha e de um seleto auditório em que predominou a classes dos professores públicos. Tratou-se de uma explanação a respeito do aparelho escolar múltiplo; se bem apertado pela urgência do pouco tempo disponível, visto que Sua Majestade, ao entrar no salão, desculpou-se por 
não poder demorar mais do que uma hora. Mesmo assim o conferencista conseguiu despertar o interesse de seus ouvintes, levando a todos, senão a convicção, a persuasão da eficácia do seu aparelho para várias disciplinas do ensino primário elementar. Depois de alguns exercícios feitos pelos alunos, crianças de 7 a 11 anos, acerca do cálculo elementar, quer sobre inteiros, quer sobre frações ordinárias decimais e sobre o sistema métrico decimal, passou a fazer com os meninos uma sucinta aplicação da parte do aparelho denominado imprensa escolar, com a qual afirmou ensinar a ler a qualquer analfabeto, dentro de 8 a 15 dias, comprometendo-se a demonstrá-lo em uma escola de adultos analfabetos, que oportunamente abrirá. E como terminasse lastimando que o curto tempo disponível fosse causar atropelo na exposição das vantagens do seu aparelho, Sua Majestade o Imperador prometeu, ao retirar-se, que o ouviria por duas horas ou mais, na próxima conferência, que talvez fosse realizada no domingo seguinte. (O Paiz, 13 nov. 1885).

Em 1887, Abílio Borges proferiu outras conferências no Rio de Janeiro. Discorreu sobre o seu método de ensino para oficiais do Batalhão de Infantaria, falando das vantagens do aparelho múltiplo escolar para o ensino da matemática. Nessa ocasião, doou à escola anexa ao batalhão de um conjunto de materiais. Na presença do comandante da corporação e dos oficiais, o pedagogista ministrou uma lição de aritmética para os soldados, explorando as operações com números inteiros, visando comprovar a eficiência do seu invento. Ao final da conferência, afirmou que estava satisfeito com os resultados, conforme noticiou o Diário de Notícias. Rio de Janeiro, em 18 de novembro de 1887.

\section{CONSIDERAÇÕES FINAIS}

Quanto à difusão dos materiais didáticos descritos neste artigo, acreditamos que um dos significados mais expressivos foi despertar o interesse de professores, como consta em relatórios da época, que, mesmo não tendo condições de adquirir os aparelhos vendidos por Abílio Borges, começaram a se apropriar da ideia, criando suas táticas de reprodução, fabricando seus próprios instrumentos do ofício. Esse interesse simbolizava o despertar da consciência docente para a modernização dos métodos de ensino.

Nesse sentido, foi o início da possibilidade de os professores serem sujeitos de suas práticas profissionais, inspiradas na cultura pedagógica da época. É o caso por exemplo de coleções de discos de cartolina, recortados em setores circulares com diferentes ângulos centrais, para ilustrar os conceitos de fração, equivalência de frações, operações elementares, entre outras noções. 
Embora nada possa ser afirmado sobre as origens remotas do material, ainda na atualidade, esses discos podem ser encontrados nos livros didáticos.

Esse retorno ao passado, leva-nos a indagar a respeito da amplitude de circulação dos materiais analisados, principalmente, nas escolas públicas provinciais, pois grande parte dos registros indicam a sua utilização em colégios particulares, destinados à instrução dos filhos das famílias mais abastadas. Nos relatórios da instrução pública do município da corte, não encontramos indicações da possível aquisição do aparelho múltiplo escolar, por parte do poder público, para a distribuição para as escolas públicas.

Um dos raros registros que conseguimos localizar, quanto ao financiamento público para aquisição de materiais didáticos para escola pública, foi a decisão pessoal do Imperador Pedro II, que mandou adquirir 100 unidades do Aritmômetros de Arens, material divulgado pelos Irmãos Lassalistas na Exposição Pedagógica de 1883 (PAIS, 2014).

No caso dos materiais didáticos criados por Abílio Borges, a produção dos mesmos estava inserida em um projeto empresarial, associado aos colégios de sua propriedade, no Rio de Janeiro e em Barbacena. Embora tenha se esforçado na estratégia de distribuir seus livros para escolas públicas, quando aos recursos materiais, ao que tudo indica, a circulação dos mesmos ocorreu quase somente em colégios particulares.

Após o falecimento do educador, ocorrido a 17 de janeiro de 1891, seus aparelhos e alguns de seus livros ainda circularam por diferentes regiões do Brasil, até o final da década de 1920, quando estava em curso as discussões iniciais da Escola Nova. Esses materiais foram expostos, por exemplo, no Primeiro Congresso de Instrução Primária de Minas Gerais, realizado de 10 a 18 de maio de 1927, porém, gerando alguns embates compreensíveis no quadro de transição daquela época. A imprensa registrou que alguns palestrantes estavam defendendo o uso do material, enquanto outros consideravam mais relevante a melhoria da formação de professores nas Escolas Normais.

O uso dos referidos materiais didáticos simbolizou a tentativa de se apropriar do que havia de mais moderno no ensino da matemática. Em particular, o material simbolizava uma maneira de se apropriar do método intuitivo e aplicá-lo ao ensino da matemática, o que ainda não tinha sido feito por outros educadores. O mérito do educador Abílio Borges poderia ser ampliado caso as obras consultadas por ele tivessem sido citadas com a devida clareza. Em síntese, houve uma 
extensa rede de apropriações, envolvendo a concepção do material, o embasamento teórico, a produção física e a ampla difusão dos mesmos em conferências.

Diante do movimento inicial da expansão da instrução primária popular no Brasil, com predomínio acentuado de discursos políticos, de modo geral, houve a tendência de valorizar recursos materiais criados no quadro de difusão do método intuitivo, priorizando o sentido da visão e admitindo a possibilidade obter resultados quase imediatos.

Ao finalizar este artigo, reconhecemos a necessidade de persistir na realização de outros estudos mais aprofundados do que foi essa primeira aproximação, no sentido de melhor explicitar o que chamamos de problema histórico dos significados atribuídos aos materiais didáticos para o ensino da matemática elementar. Na possível definição de outras questões relacionadas à mesma temática, visualizamos o desafio de retornar ao quadro cultural dos últimos anos do século XIX. Assim poderemos melhor compreender a trajetória dos educadores que protagonizaram a educação do tempo considerado e cumpriram o desafio profissional de materializar conceitos matemáticos e abstrair o que aparece na exterioridade dos materiais didáticos.

\section{REFERÊNCIAS}

ALVES, Cláudia. Educação, Memória e Identidade: dimensões imateriais da cultura material escolar. História da Educação, Univ. Federal de Pelotas, v. 14, n. 30, p. 101-125, 2010.

ALVES, Isaias. Vida e Obra do Barão de Macaúbas. Coleção Centro de Estudos Pedagógicos. Rio de Janeiro: Oficina Gráfica Renato Americano, 1936.

BLOCH, Marc. Apologia da História ou o Ofício do Historiador. Rio de janeiro: Zahar, 2002.

BURKE, Peter. O que é história cultural. 2. ed. Rio de Janeiro: Zahar, 2008.

CERTEAU, Michel de. A invenção do cotidiano. Petrópolis: Vozes. 1998.

CHARTIER, Roger. Formas e Sentido. Cultura escrita: entre distinção e apropriação. Campinas. SP: Mercado de Letras, 2003.

CHER VEL, André. La Culture Sclaire. Une approche historique. Paris: Belin, 98.

DIÁRIO DE NOTÍCIAS, Rio de Janeiro, 9 out. 1885.

JULIA, Dominique; A cultura escolar como objeto histórico. Revista Brasileira de História da Educação, Campinas, n. 1, p. 9-43, 2001. 
O Paiz. São Luiz do Maranhão, 13 nov. 1885.

PAIS, Luiz Carlos. História dos aritmômetros escolares no ensino primário da matemática no Brasil (1883-1927). Em Teia - Revista de Educação Matemática, Recife, v. 5, n. 2, 2014.

SAUSSURE, Ferdinand. Curso de Linguística Geral. 30. ed. São Paulo: Cultrix, 2002.

SCHELBAUER, A. R. O método intuitivo e lições de coisas no Brasil do século XIX. In: STEPHANOU, Maria; BASTOS, Maria Helena. História e Memórias da Educação no Brasil. 2. ed. Petrópolis: Vozes, 2006. (Vol. II)

Recebido em: 16 de maio de 2019

Aceito em: 26 de outubro de 2019 